\title{
Thermoanalytical, Spectroscopic and DFT Studies of Heavy Trivalent Lanthanides and Yttrium(III) with Oxamate as Ligand
}

\author{
Flávio Junior Caires ${ }^{a *}$, Wilhan Donizete Gonçalves Nunes ${ }^{b}$, Caroline Gaglieri ${ }^{a}$, André Luiz \\ Carneiro Soares do Nascimento ${ }^{b}$,José Augusto Teixeira ${ }^{b}$, Geórgia Alvim Coelho Zangaro ${ }^{b}$, \\ Oswaldo Treu-Filho ${ }^{b}$, Massao Ionashiro ${ }^{b}$ \\ a Faculdade de Ciências, Universidade Estadual Paulista Júlio de Mesquita Filho - UNESP, \\ Bauru, SP, Brazil \\ ${ }^{b}$ Instituto de Quimica, Universidade Estadual Paulista Júlio de Mesquita Filho - UNESP, \\ Araraquara, SP, Brazil
}

Received: September 01, 2016; Revised: April 18, 2017; Accepted: May 21, 2017

\begin{abstract}
Solid-state $\mathrm{LnL}_{3} \cdot n \mathrm{H}_{2} \mathrm{O}$ complexes, where $\mathrm{Ln}$ stands for trivalent lanthanides ( $\mathrm{Tb}$ to $\mathrm{Lu}$ ) or yttrium(III) and $\mathrm{L}$ is oxamate $\left(\mathrm{NH}_{2} \mathrm{COCO}_{2}^{-}\right)$, have been synthesized. The characterization of the complexes was performed by using elemental analysis (EA), complexometric titration with EDTA, thermoanalytical techniques such as simultaneous thermogravimetry and differential scanning calorimetry (TG-DSC), evolved gas analysis (TG-FTIR), infrared spectroscopy (IR) and powder X-ray diffraction (XRPD). The results provided information about thermal behavior, crystallinity, stoichiometry, coordination sites, as well as the products released during thermal degradation of the complexes studied. Theoretical calculation of yttrium oxamate, as representative of all complexes was performed using density functional theory (DFT) for studying the molecular structure and vibrational spectrum of the investigated molecule in the ground state. The optimized geometrical parameters and theoretical vibrational spectrum obtained by DFT calculations are in good agreement with the experimental results.
\end{abstract}

Keywords: Lanthanides, Oxamic acid, Thermal analysis, DFT calculations

\section{Introduction}

The oxamic acid is composed of carboxyl group and primary amide group and molecular formula $\mathrm{C}_{2} \mathrm{H}_{3} \mathrm{NO}_{3}$. It has molar mass of $89.05 \mathrm{~g} \mathrm{~mol}^{-1}$, odorless, sublimates and melts partly around $140^{\circ} \mathrm{C}$ and it is found as a white solid.

The oxamic acid is well known as a versatile ligand and can act as di, tri or tetradentate (bridging) regarding its coordination modes, or as mono or dianion, when the charge is taken into account. When treated as a monoanion, it can coordinate by two of its oxygen atoms, forming a fivemembered chelate ring, or by one oxygen atom (from the carboxylate group) and the nitrogen (amide group). Still as a monoanion it can act as a monodentate ligand using one oxygen atom from the carboxylic group; or as a tridentate ligand using all of its oxygen atoms. In the dianion form, when it loses of its ionisable hydrogens, it can act as a chelate bidentate or bridging ligand, and also as bridging tetradentate ligand in binuclear complexes, which also can contain other multidentate chelate ligands ${ }^{1}$.

A few studies about complexes involving lanthanides and oxamic acid are found in the literature. Two of them describe the synthesis, the determination of physical properties,

* e-mail: caires.flavio@fc.unesp.br spectroscopic studies and thermal behavior of lanthanide (III) oxamates ${ }^{2,3}$. The others reported the crystal structure determination of the oxamate praseodymium, neodymium, and holmium ${ }^{1,4,5}$.

The present paper reports the preparation of solid-state complexes of heavy trivalent lanthanides with oxamate and the investigation by means of complexometry, elemental analysis, simultaneous thermogravimetry and differential scanning calorimetry (TG-DSC), TG-DSC coupled to FTIR, powder X-ray diffraction (PXRD) and infrared spectroscopy (FTIR). DFT calculations were performed in order to compare and support the experimental results. This work is primarily a continuation and extension of the reported study on the thermal behavior of light trivalent lanthanide oxamates ${ }^{6}$.

\section{Experimental}

The oxamic acid, $\mathrm{H}_{2} \mathrm{NCOCOOH}$, with $99 \%$ purity was obtained from Sigma and used as received.

The basic carbonates of heavy trivalent lanthanides ( $\mathrm{Tb}$ to $\mathrm{Lu}$ ) and yttrium (III) were prepared following the procedure described in the literature ${ }^{6}$.

Solid-state heavy trivalent lanthanide and yttrium oxamates were prepared following the literature method $^{6}$ : 
Under stirring, slight excess of the corresponding metal basic carbonate was added to $50 \mathrm{~mL}$ of an aqueous suspension of oxamic acid $0.15 \mathrm{~mol} \mathrm{~L}^{-1}$.

For the solid-state complexes, metal ions, hydration water, and oxamate contents were determined from TG curves. The metal ions were also determined by complexometry with standard EDTA solution after igniting the complexes to the respective oxides and their dissolution in hydrochloric acid solution ${ }^{6}$.

Carbon, hydrogen and nitrogen contents were determined by microanalytical procedures, with a CHN Elemental Analyzer from Perkin Elmer, model 2400.

Simultaneous TG-DSC curves were obtained in a Mettler Toledo TG-DSC 1 thermal analysis system. The purge gas was dry air with flow of $50 \mathrm{~mL} \mathrm{~min}{ }^{-1}$. Heating rate of $10^{\circ} \mathrm{C}$ $\mathrm{min}^{-1}$ was used, with samples weighing about $7.0 \mathrm{mg}$. Alumina crucibles were used for recording the TG-DSC curves.

The evolved gas analysis (EGA) was performed using a Mettler TG-DSC thermogravimetric analyzer coupled to a Nicolet FTIR spectrophotometer with gas cell and DTGS $\mathrm{KBr}$ detector. The TG furnace and heated gas cell $\left(250^{\circ} \mathrm{C}\right)$ were coupled through a heated $\left(225^{\circ} \mathrm{C}\right) 120 \mathrm{~cm}$ stainless steel line transfer with diameter of $3.0 \mathrm{~mm}$, both purged with dry air $\left(50 \mathrm{~mL} \mathrm{~min}^{-1}\right)$. The FTIR spectra were recorded with 16 scans per spectrum at a resolution of $4 \mathrm{~cm}^{-1}$.

X-ray powder diffraction (XRPD) data were obtained by using a Siemens D-5000 X-Ray Diffractometer employing $\mathrm{CuK} \alpha$ radiation $(\lambda=1.541 \AA$ ) and setting of $40 \mathrm{kV}$ and $20 \mathrm{~mA}$.

The attenuate total reflectance infrared spectra of sodium oxamate as well as of its metal-ion complexes were recorded using a Nicolet iS10 FTIR spectrophotometer, using an ATR accessory with a Ge window. The FTIR spectra were recorded with 32 scans per spectrum at resolution of $4 \mathrm{~cm}^{-1}$.

\subsection{Computational strategy}

In this study, the quantum chemical approach employed to determine the molecular structures was Becke's three parameter hybrid theory ${ }^{7}$ using the Lee-Yang-Par (LYP) correlation functional ${ }^{8}$, and the basis sets used for calculations were: $4 \mathrm{~s}$ for $\mathrm{H}\left({ }^{2} \mathrm{~S}\right)^{9}$, $[5 \mathrm{~s} 4 \mathrm{p}]$ for $\mathrm{C}\left({ }^{3} \mathrm{P}\right), \mathrm{N}\left({ }^{4} \mathrm{~S}\right)$ and $\mathrm{O}\left({ }^{3} \mathrm{P}\right)$ $(9)$, and $[14 \mathrm{~s} 7 \mathrm{p} 7 \mathrm{~d}]$ for $\mathrm{Y}\left({ }^{2} \mathrm{D}\right)^{10}$. The diffuse functions for the yttrium atom $\left({ }^{2} \mathrm{D}\right)$ were calculated according to the procedure described by Teu-Filho et al. ${ }^{9}$ and these values are: $\alpha \mathrm{s}=$ $0.007007235, \alpha p=0.991840315, \alpha d=0.008880095$. Full details about the wave function developed in this work are available upon request to the e-mail address: oswaldo.treu. filho@gmail.com.

In order to better describe the properties of the complex in the implementation of the calculations, it was necessary to include polarization functions ${ }^{9-11}$ for all atoms of the complex. The polarization functions are: $\alpha \mathrm{p}=0.33353749$ for $\mathrm{H}\left({ }^{2} \mathrm{~S}\right)$, $\alpha d=0.72760279, \alpha d=0.35416230 \alpha d=0.36059494$ for $\mathrm{C}$ $\left({ }^{3} \mathrm{P}\right), \mathrm{N}\left({ }^{4} \mathrm{~S}\right)$ and $\mathrm{O}\left({ }^{3} \mathrm{P}\right)$, respectively, and $\alpha \mathrm{f}=0.394056689$ for
$\mathrm{Y}\left({ }^{2} \mathrm{D}\right)$ atoms. The role of a basis set is crucial in theoretical studies of metal complexes, since the description of the metal configuration in the complex differs from the neutral state. The performed molecular calculations in this study were made using the Gaussian 09 routine ${ }^{12}$.

The theoretical infrared spectrum was calculated using a harmonic field ${ }^{13}$ based on $\mathrm{C}_{1}$ symmetry (electronic state ${ }^{1} \mathrm{~A}$ ). Frequency values (not scaled), relative intensities, assignments, and description of vibrational modes are presented. The geometry optimization was computed using the optimized algorithm of Berny ${ }^{14}$ and the calculations of vibrational frequencies were also implemented to determine if the optimized geometry constitutes minimum or saddle points . The principal infrared active fundamental mode assignments and descriptions were done by the GaussView 5.0.2 W graphics routine ${ }^{15}$.

\section{Results and Discussion}

\subsection{Analytical results}

The analytical and thermoanalytical (TG) results for the synthesized complexes are shown in Table 1. The analytical results are in good agreement with the thermoanalytical ones, evidencing that the complexes were obtained in a high degree of purity. From the results, it was possible to establish the stoichiometry of the complexes, which is in agreement with the general formula: $\mathrm{Ln}(\mathrm{L})_{3} \cdot n \mathrm{H}_{2} \mathrm{O}$, where $\mathrm{Ln}$ represents heavy trivalent lanthanides, $\mathrm{L}$ is oxamate and $\mathrm{n}=1$ (Dy, Ho, Y); $1.25(\mathrm{Er}) ; 1.5$ (Tb and Lu); 2 (Tm) and $2.5(\mathrm{Yb})$.

\subsection{Thermal analysis (TG-DSC and EGA)}

The simultaneous TG-DSC curves of the complexes are shown in Figure 1. In all complexes, the TG curves show mass losses in four consecutive and/or overlapping steps, although the DSC curves show that the thermal decomposition occurs with a large number of consecutive and/or simultaneous steps and through a more complex pathway than that observed in the TG curves. The mass losses corresponding to endothermic peaks are attributed to the dehydration or thermal decomposition and the exothermic ones to the oxidation of the organic matter and/or of the gaseous products evolved during the thermal decomposition.

The thermal decomposition reaction interval (I) from anhydrous complexes and final temperature of thermal decomposition (II) as shown by the curves TG-DSC depends on the nature of the metal ion and they follow the order:

$$
\begin{aligned}
& \text { (I) Ho }>\text { Y = Er = Dy }>\text { Lu }>\text { Tm }>\text { Yb }>\text { Tb } \\
& \text { (II) Er }>\text { Ho }>\text { Lu }=\text { Y }>\text { Dy }>\text { Tm }>\text { Yb }>\text { Tb }
\end{aligned}
$$

A great similarity is observed in the profiles of the TG curves, except for the terbium complex. On the other hand, 
Table 1. Analytical and thermoanalytical (TG) data for $\mathrm{Ln}(\mathrm{L})_{3} \cdot n \mathrm{H}_{2} \mathrm{O}$ complexes.

\begin{tabular}{|c|c|c|c|c|c|c|c|c|c|c|c|c|c|c|}
\hline \multirow{2}{*}{ Complexes } & \multicolumn{2}{|c|}{ Ln (oxide) / \% } & \multicolumn{3}{|c|}{$\mathrm{L}($ lost $) / \%$} & \multicolumn{2}{|c|}{$\mathrm{H}_{2} \mathrm{O} / \%$} & \multicolumn{2}{|c|}{$\mathrm{C} / \%$} & \multicolumn{2}{|c|}{$\mathrm{H} / \%$} & \multicolumn{2}{|c|}{$\mathrm{N} / \%$} & \multirow{2}{*}{$\begin{array}{c}\text { Final } \\
\text { Residue }\end{array}$} \\
\hline & Calc. & EDTA & TG & $C_{0} 1 \mathrm{~s}$ & TG & Calc. & TG & alc. & EA & & EA & Calc. & EA & \\
\hline $\mathrm{Tb}(\mathrm{L})_{3} \cdot 1.5 \mathrm{H}_{2} \mathrm{O}$ & 39.77 & 39.50 & 977 & 52.21 & 52.64 & 6.01 & & 16.01 & & & & & & $\mathrm{~Tb}_{4} \mathrm{O}_{7}$ \\
\hline $\mathrm{Dy}(\mathrm{L})_{3} \cdot 1 \mathrm{H}_{2} \mathrm{O}$ & & & & & & 4.05 & & & & & & & & $\mathrm{Dy}_{2} \mathrm{O}_{3}$ \\
\hline $\mathrm{Ho}(\mathrm{L})_{3} \cdot 1 \mathrm{H}_{2} \mathrm{O}$ & 42.26 & 42.06 & 72.01 & ד & 53.81 & 4.03 & 3.88 & 16.12 & 16.10 & 1.01 & 1.01 & 9.40 & 9.39 & $\mathrm{Ho}_{2} \mathrm{O}_{3}$ \\
\hline $\mathrm{Er}(\mathrm{L})_{3} \cdot 1.25 \mathrm{H}_{2} \mathrm{O}$ & 42.14 & & 41.36 & & & 5.90 & & 15.88 & & & & & 9.38 & $\mathrm{Er}_{2} \mathrm{O}_{3}$ \\
\hline $\operatorname{Tm}(\mathrm{L})_{3} \cdot 2 \mathrm{H}_{2} \mathrm{O}$ & 41.13 & 40.97 & 41.18 & 51.19 & 51.53 & 7.68 & 7.29 & 15.36 & 15.35 & 2.15 & 2.15 & 8.96 & 8.95 & $\mathrm{Tm}_{2} \mathrm{O}_{3}$ \\
\hline $\mathrm{Yb}(\mathrm{L})_{3} \cdot 2.5 \mathrm{H}_{2} \mathrm{O}$ & 40.86 & 40.39 & 40.51 & 49.79 & 50.37 & 9.34 & 9.12 & 14.94 & 15.03 & 2.30 & 2.32 & 8.72 & 8.77 & $\mathrm{Yb}_{2} \mathrm{O}_{3}$ \\
\hline $\mathrm{Lu}(\mathrm{L})_{3} \cdot 1.5 \mathrm{H}_{2} \mathrm{O}$ & 42.69 & 42.40 & 42.83 & 51.52 & 51.39 & 5.80 & 5.78 & 15.46 & 15.42 & 1.95 & 1.95 & 9.02 & 8.99 & $\mathrm{Lu}_{2} \mathrm{O}_{3}$ \\
\hline $\mathrm{Y}(\mathrm{L})_{3} \cdot 1 \mathrm{H}_{2} \mathrm{O}$ & 30.43 & 30.20 & 30.46 & 64.71 & 64.64 & 4.86 & 4.90 & 19.42 & 19.41 & 2.18 & 2.18 & 11.33 & 11.32 & $\mathrm{Y}_{2} \mathrm{O}_{3}$ \\
\hline
\end{tabular}

L: oxamate.
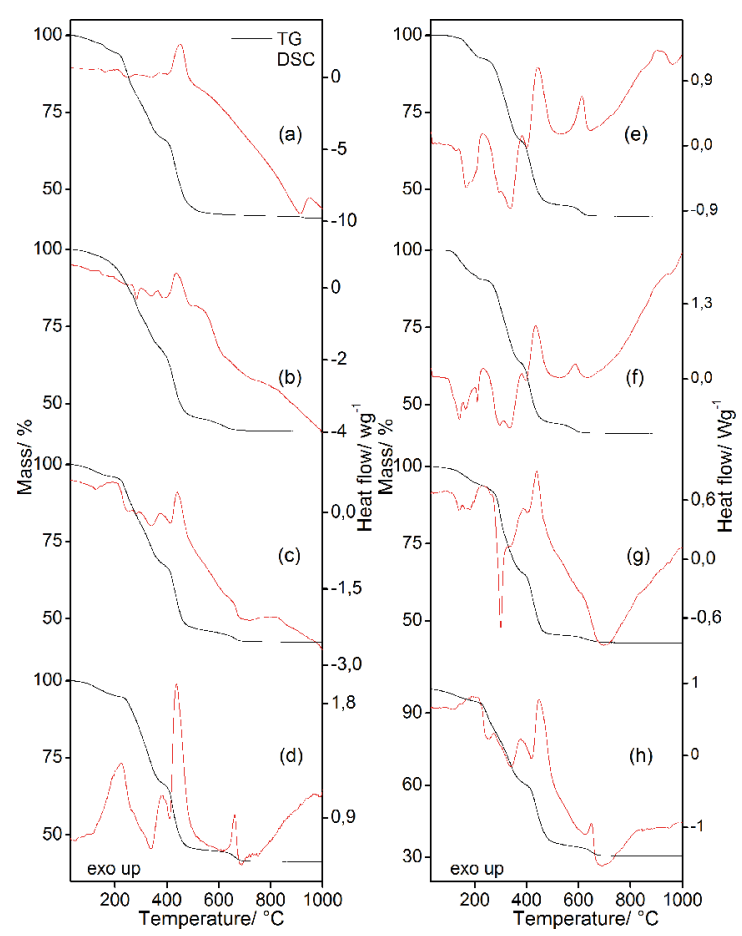

Figure 1. Simultaneous TG-DSC curves of the complexes: (a) $\mathrm{Tb}(\mathrm{L})_{3} \cdot 1.5 \mathrm{H}_{2} \mathrm{O},(\mathrm{b}) \mathrm{Dy}(\mathrm{L})_{3} \cdot 1 \mathrm{H}_{2} \mathrm{O},(\mathrm{c}) \mathrm{Ho}(\mathrm{L})_{3} \cdot 1 \mathrm{H}_{2} \mathrm{O},(\mathrm{d}) \mathrm{Er}(\mathrm{L})_{3} \cdot 1.25 \mathrm{H}_{2} \mathrm{O}$, (e) $\mathrm{Tm}(\mathrm{L})_{3} \cdot 2 \mathrm{H}_{2} \mathrm{O}$, (f) $\mathrm{Yb}(\mathrm{L})_{3} \cdot 2.5 \mathrm{H}_{2} \mathrm{O},(\mathrm{g}) \mathrm{Lu}(\mathrm{L})_{3} \cdot 1.5 \mathrm{H}_{2} \mathrm{O}$ and (h) $\mathrm{Y}(\mathrm{L})_{3} \cdot 1 \mathrm{H}_{2} \mathrm{O}$.

the profiles of the DSC curves show great similarity for two sets of complexes (Tb, Dy, Ho and Tm, Yb) and particular ones for the other complexes (Er, Lu and Y), as also observed in all DSC curves of the trivalent light lanthanide oxamates ${ }^{6}$. Thus, the features of each complex are discussed based on their similar thermal profiles from TG curves.

\section{Terbium complex}

The TG-DSC curves of the complex are shown in Figure 1 (a). These curves show mass losses in four steps and thermal events corresponding to these losses. The first mass loss that occurs through a slow process corresponding to an endothermic peak is attributed to dehydration.
The thermal decomposition of the anhydrous complexes occurs in three steps immediately after the dehydration and the first two mass losses corresponding to endothermic peaks are attributed to the thermal decomposition and an exothermic peak due to the oxidation of organic matter and/or of the gaseous products evolved in the thermal decomposition, with the formation of terbium oxide, $\mathrm{Tb}_{4} \mathrm{O}_{7}$. The last mass loss between 900 and $940^{\circ} \mathrm{C}$ corresponding to an endothermic peak at $910^{\circ} \mathrm{C}$ is attributed to reduction reaction of $\mathrm{Tb}_{4} \mathrm{O}_{7}$ to $\mathrm{Tb}_{2} \mathrm{O}_{3}$, as already observed in other studies ${ }^{16,17}$.

\section{Dysprosium to lutetium and yttrium}

The TG-DSC curves of these complexes are shown in Figure $1(b-h)$. These curves also show mass losses in four steps and thermal events corresponding to these losses. The first mass loss that occurs slowly corresponding to an endothermic peak (Ho, Tm, Y), and two (Dy) or three endothermic peak $(\mathrm{Yb}, \mathrm{Lu})$ is attributed to dehydration.

After the dehydration, the thermal decomposition of the anhydrous complexes occurs in three steps. The first two - corresponding to endothermic peaks - are attributed to the thermal decomposition, and the last - associated with an exothermic peak - is attributed to the oxidation of organic matter and/or of the gaseous products evolved in the thermal decomposition, with the formation of a mixture of carbonaceous residue and a derivative of carbonate. Tests with hydrochloric acid solution on samples heated up to the temperature of formation of this mixture, as indicated by the corresponding TG-DSC curves confirmed the formation of carbonate by the evolution of $\mathrm{CO}_{2}$ and the presence of carbonaceous residue. The formation of carbonaceous residue and of derivative of carbonate had already been observed in the thermal decomposition of some light trivalent lanthanide oxamates $^{6}$ and other lanthanide complexes ${ }^{18,19}$.

The last mass loss corresponding to no thermal events (Dy, Lu), small endothermic peak (Ho) or exothermic peaks (Er, Tm, Yb, Y) is attributed to oxidation of carbonaceous residue (exo) and thermal decomposition of the derivative of carbonate (endo). Calculations based on the mass losses 
observed in the TG curves are in agreement with the formation of the respective oxides, $\mathrm{Ln}_{2} \mathrm{O}_{3}(\mathrm{Ln}=\mathrm{Tb}$ to $\mathrm{Lu}$ and $\mathrm{Y})$ and confirmed by X-ray powder patterns.

In spite of the similarity in the TG profiles of these complexes, the temperature ranges $(\theta)$, mass losses $(\mathrm{m})$ and temperature peaks (p) observed in each steps of the TG-DSC curves are characteristic of each complex, and for that reason this information is provided in Table 2.

\section{EGA}

The Gram-Schmidt curves (GS) and the IR spectra of the gaseous products released during the thermal decomposition of the thulium complex, as representative of all the complexes, are presented in Figure 2. In general, GS curves are very similar to DTG curves (supplementary material), and thus their profiles can be correlated to the number of mass loss steps. The differences that may arise between them are probably due to the fact that GS curve profile is related to the molar absorption coefficient of the molecules of gases while the DTG curve is related to mass variation. The GS curve shows four maximum-intensity regions, and the second consisting of two maximum values (two peaks). This suggests that the thermal decomposition takes place in at least four steps, and can be confirmed by inspecting the second mass loss in the TG curve, that is formed by at least two overlapping steps, as confirmed by the DTG curve. In addition, the GS curve shows that all steps are superposed, in agreement with the TG/DTG-DSC curves.

The gases released during the thermal decomposition were identified based on FTIR reference spectra available in the spectrometer's software database and analysis of the frequencies of the vibrational modes. The spectra obtained up to approximately $200{ }^{\circ} \mathrm{C}$ show characteristic bands of water vapor $(v \mathrm{O}-\mathrm{H}$ in the range $4000-3400 \mathrm{~cm}^{-1}$ and $\delta \mathrm{O}-\mathrm{H}$ in the range of 2060 to $1260 \mathrm{~cm}^{-1}$ ) attributed to dehydration of the complexes, as indicated by curves TG-DSC. Above $200{ }^{\circ} \mathrm{C}$, the main gas species identified were ammonia (characteristic bands at 3334 $\mathrm{cm}^{-1}\left(\mathrm{NNH}_{3}\right)$ and $1626,966 \mathrm{~cm}^{-1}\left(\delta \mathrm{NH}_{3}\right), \mathrm{CO}_{2}$ (characteristic absorption bands at 2355 and $2311 \mathrm{~cm}^{-1}\left(v \mathrm{VO}_{2}\right)$ and $669 \mathrm{~cm}^{-1}\left(\delta \mathrm{CO}_{2}\right)$; $\mathrm{CO}$ (characteristic band at $2154 \mathrm{~cm}^{-1}(v$ $\mathrm{CO})$ ) $\mathrm{N}_{2} \mathrm{O}$ (characteristic band at $2220 \mathrm{~cm}^{-1}$ ), $\mathrm{HCN}$ (bands at $3300 \mathrm{~cm}-1\left(v \mathrm{C}-\mathrm{H}\right.$ and $\left.712 \mathrm{~cm}^{-1}(\delta \mathrm{HCN})\right)$.

Table 2. Temperature ranges $(\theta)$, mass losses $(\Delta \mathrm{m})$ and peak temperatures (Tp) observed for each step of TG-DSC curves of the complexes.

\begin{tabular}{|c|c|c|c|c|c|c|}
\hline \multirow{2}{*}{ Complexes } & \multicolumn{5}{|c|}{ TG-DSC Steps } & \multirow{2}{*}{$\Delta \mathrm{m}_{\text {Tota }}$} \\
\hline & & First & Second & Third & Fourth & \\
\hline \multirow{3}{*}{$\mathrm{Tb}(\mathrm{L})_{3} \cdot 1.5 \mathrm{H}_{2} \mathrm{O}$} & $\theta /{ }^{\circ} \mathrm{C}$ & $55-205$ & $205-370$ & $370-600$ & $900-940$ & \multirow{3}{*}{59.36} \\
\hline & $\mathrm{T}_{\mathrm{p}} /{ }^{\circ} \mathrm{C}$ & $170 \downarrow$ & $250 \downarrow, 340 \downarrow$ & $450 \uparrow$ & $910 \downarrow$ & \\
\hline & $\Delta \mathrm{m} / \%$ & 5.57 & 27.06 & 25.36 & 1.37 & \\
\hline \multirow{3}{*}{$\operatorname{Dy}(\mathrm{L})_{3} \cdot 1 \mathrm{H}_{2} \mathrm{O}$} & $\theta /{ }^{\circ} \mathrm{C}$ & $55-190$ & $190-360$ & $360-530$ & $530-670$ & \multirow{3}{*}{58.98} \\
\hline & $\mathrm{T}_{\mathrm{p}} /{ }^{\circ} \mathrm{C}$ & $120 \downarrow \mathrm{sm}, 160 \downarrow \mathrm{sm}, 175 \downarrow \mathrm{sm}$ & $285 \downarrow, 340 \downarrow$ & $435 \uparrow$ & - & \\
\hline & $\Delta \mathrm{m} / \%$ & 4.31 & 26.14 & 24.36 & 4.17 & \\
\hline \multirow{3}{*}{$\mathrm{Ho}(\mathrm{L})_{3} \cdot 1 \mathrm{H}_{2} \mathrm{O}$} & $\theta /{ }^{\circ} \mathrm{C}$ & $55-190$ & $190-370$ & $370-500$ & $500-690$ & \multirow{3}{*}{57.69} \\
\hline & $\mathrm{T}_{\mathrm{p}} /{ }^{\circ} \mathrm{C}$ & $132 \downarrow, 155 \downarrow \mathrm{sh}$ & $250 \downarrow, 285 \downarrow \mathrm{sh}, 340 \downarrow$ & $415 \downarrow, 440 \uparrow$ & $680 \downarrow$ & \\
\hline & $\Delta \mathrm{m} / \%$ & 3.88 & 27.11 & 21.92 & 4.78 & \\
\hline \multirow{3}{*}{$\mathrm{Er}(\mathrm{L})_{3} \cdot 1.25 \mathrm{H}_{2} \mathrm{O}$} & $\theta /{ }^{\circ} \mathrm{C}$ & $55-220$ & $220-385$ & $385-530$ & $530-700$ & \multirow{3}{*}{58.64} \\
\hline & $\mathrm{T}_{\mathrm{p}} /{ }^{\circ} \mathrm{C}$ & - & $340 \downarrow$ & $410 \downarrow, 435 \uparrow$ & $660 \uparrow$ & \\
\hline & $\Delta \mathrm{m} / \%$ & 5.12 & 28.21 & 21.42 & 3.89 & \\
\hline \multirow{3}{*}{$\operatorname{Tm}(\mathrm{L})_{3} \cdot 2 \mathrm{H}_{2} \mathrm{O}$} & $\theta /{ }^{\circ} \mathrm{C}$ & $100-215$ & $215-370$ & $370-500$ & $500-630$ & \multirow{3}{*}{58.82} \\
\hline & $\mathrm{T}_{\mathrm{p}} /{ }^{\circ} \mathrm{C}$ & $125 \downarrow, 162 \downarrow, 180 \downarrow \mathrm{sh}$ & $330 \downarrow$ & $390 \downarrow, 435 \uparrow$ & $605 \uparrow$ & \\
\hline & $\Delta \mathrm{m} / \%$ & 7.29 & 26.95 & 20.52 & 4.06 & \\
\hline \multirow{3}{*}{$\mathrm{Yb}(\mathrm{L})_{3} \cdot 2.5 \mathrm{H}_{2} \mathrm{O}$} & $\theta /{ }^{\circ} \mathrm{C}$ & $100-210$ & $210-365$ & $365-470$ & $470-620$ & \multirow{3}{*}{59,49} \\
\hline & $\mathrm{T}_{\mathrm{p}} /{ }^{\circ} \mathrm{C}$ & $140 \downarrow, 160 \downarrow, 205 \downarrow$ & $290 \downarrow, 325 \downarrow$ & $390 \downarrow, 425 \uparrow$ & $580 \uparrow$ & \\
\hline & $\Delta \mathrm{m} / \%$ & 9.12 & 27.08 & 19.38 & 3.91 & \\
\hline \multirow{3}{*}{$\mathrm{Lu}(\mathrm{L})_{3} \cdot 1.5 \mathrm{H}_{2} \mathrm{O}$} & $\theta /{ }^{\circ} \mathrm{C}$ & $55-220$ & $220-385$ & $385-470$ & $470-680$ & \multirow{3}{*}{57.17} \\
\hline & $\mathrm{T}_{\mathrm{p}} /{ }^{\circ} \mathrm{C}$ & $145 \downarrow, 170 \downarrow, 185 \downarrow$ & $262 \downarrow \mathrm{sh}, 300 \downarrow, 330 \downarrow \mathrm{sh}$ & $400 \downarrow, 440 \uparrow$ & - & \\
\hline & $\Delta \mathrm{m} / \%$ & 5.78 & 28.69 & 19.30 & 3.40 & \\
\hline \multirow{3}{*}{$\mathrm{Y}(\mathrm{L})_{3} \cdot 1 \mathrm{H}_{2} \mathrm{O}$} & $\theta /{ }^{\circ} \mathrm{C}$ & $50-200$ & $200-370$ & $370-510$ & $510-680$ & \multirow{3}{*}{69.54} \\
\hline & $\mathrm{T}_{\mathrm{p}} /{ }^{\circ} \mathrm{C}$ & $130 \downarrow, 155 \downarrow$ sh & 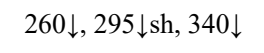 & $420 \downarrow, 445 \uparrow$ & $640 \uparrow$ & \\
\hline & $\Delta \mathrm{m} / \%$ & 4.90 & 32.62 & 26.52 & 5.50 & \\
\hline
\end{tabular}



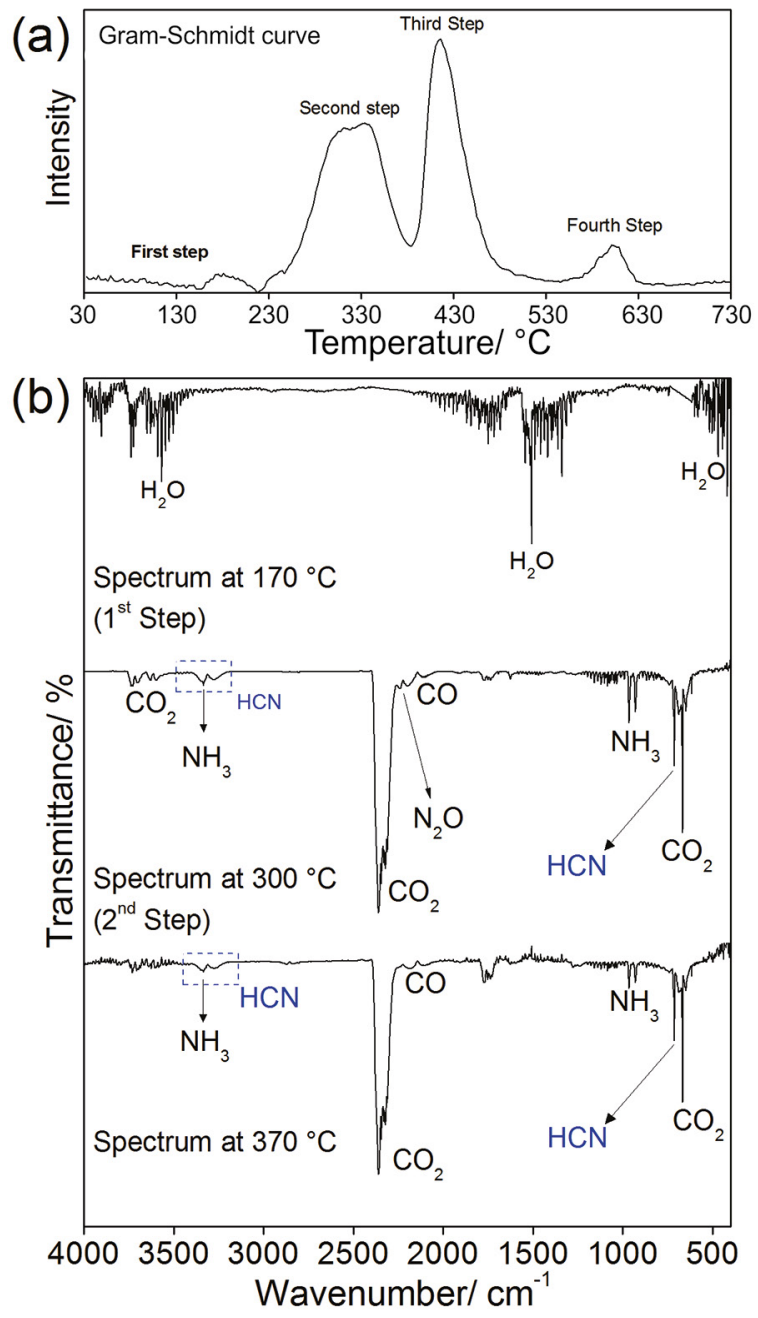

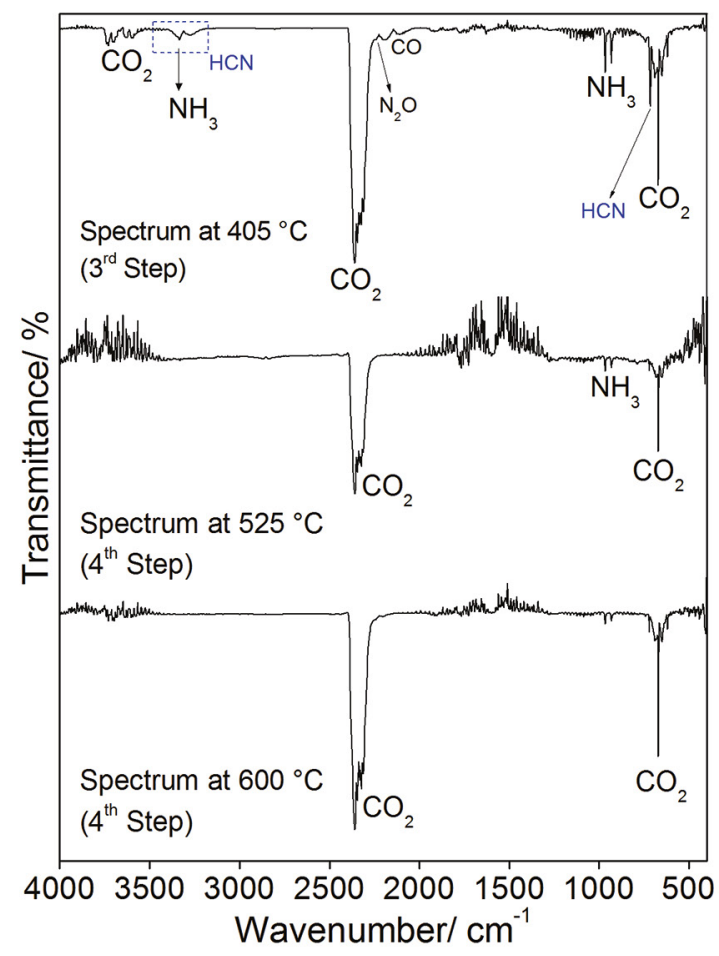

Figure 2. (a) Gram-Schmidt curve and (b) IR spectra of gaseous products evolved during the thermal decomposition of the yttrium complex.

Spectrum obtained at $600^{\circ} \mathrm{C}$ shows characteristic bands of $\mathrm{CO}_{2}$ molecule, in accordance with the decomposition of the carbonate derivative with formation of thulium oxide.

\subsection{Molecular modeling and vibrational spectroscopy in the infrared region}

The calculated geometries are shown in Figure 3. Theoretical calculations showed that the structure in Fig $3 \mathrm{a}$ (isomer 1) is 10.90, 22.24 and $34.86 \mathrm{kcal} \mathrm{mol}^{-1}$ more stable than the structures $3 \mathrm{~b}$ (isomer 2), $3 \mathrm{c}$ (isomer 3 ) and $3 \mathrm{~d}$ (isomer 4) respectively. These theoretical results suggest that the ligand oxamate coordinates to the metal center in a bidentate mode, by one of the oxygen atoms from the carboxylate group and the oxygen atom of the amide group forming a chelate five membered ring (Figure 3a), agreeing with the structure determined by single crystal X-ray diffraction ${ }^{1}$. The structural parameters obtained from the most stable structure are shown in the supplemental material (Table S1).
The vibrational spectra in the infrared region of the oxamic acid, sodium oxamate, lanthanide complex and the calculated from the more stable structure of the yttrium complex are shown in Figure 4.

The assignments were made based on theoretical calculations and also on the existing literature ${ }^{20,21}$ and are presented in Table 3.

Comparative analysis of some bands observed in the experimental and theoretical spectra shows: (i) a band at 1683 $\mathrm{cm}^{-1}$, while the theoretical result shows the corresponding peak at $1744 \mathrm{~cm}^{-1}$ with $3.62 \%$ discrepancy; (ii) a very strong band at $1638 \mathrm{~cm}^{-1}$, while the theoretical spectrum shows the band corresponding to $1689 \mathrm{~cm}^{-1}$, resulting in a $3.11 \%$ discrepancy; and (iii) a strong band at $1318 \mathrm{~cm}^{-1}$, while the theoretical result shows the corresponding band in at 1295 $\mathrm{cm}^{-1}$, a $1.75 \%$ discrepancy. The theoretical results are in very good agreement with the experimental data suggesting that the structure shown in Figure $3 \mathrm{a}$ can represent or be close to the real structure. 


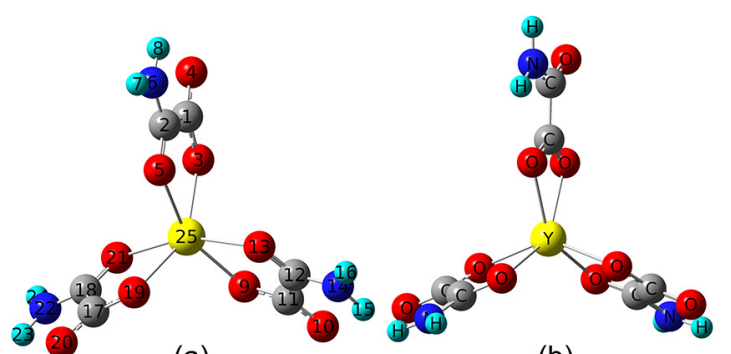

(a)

(b)

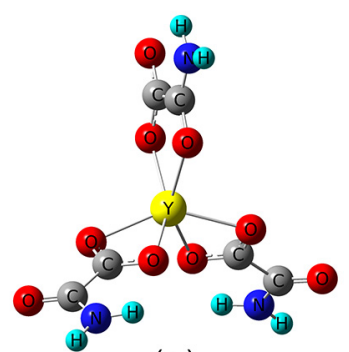

(c)

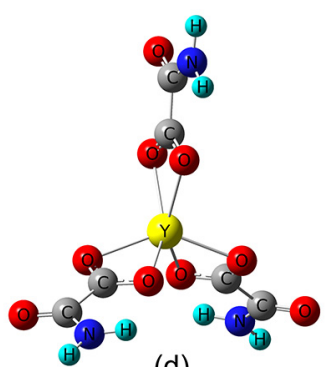

(d)

Figure 3. Optimized geometric structure of the $Y(L) 3$ : (a) Isomer 1 (more stable), (b) isomer 2, (c) isomer 3 and (d) isomer 4.

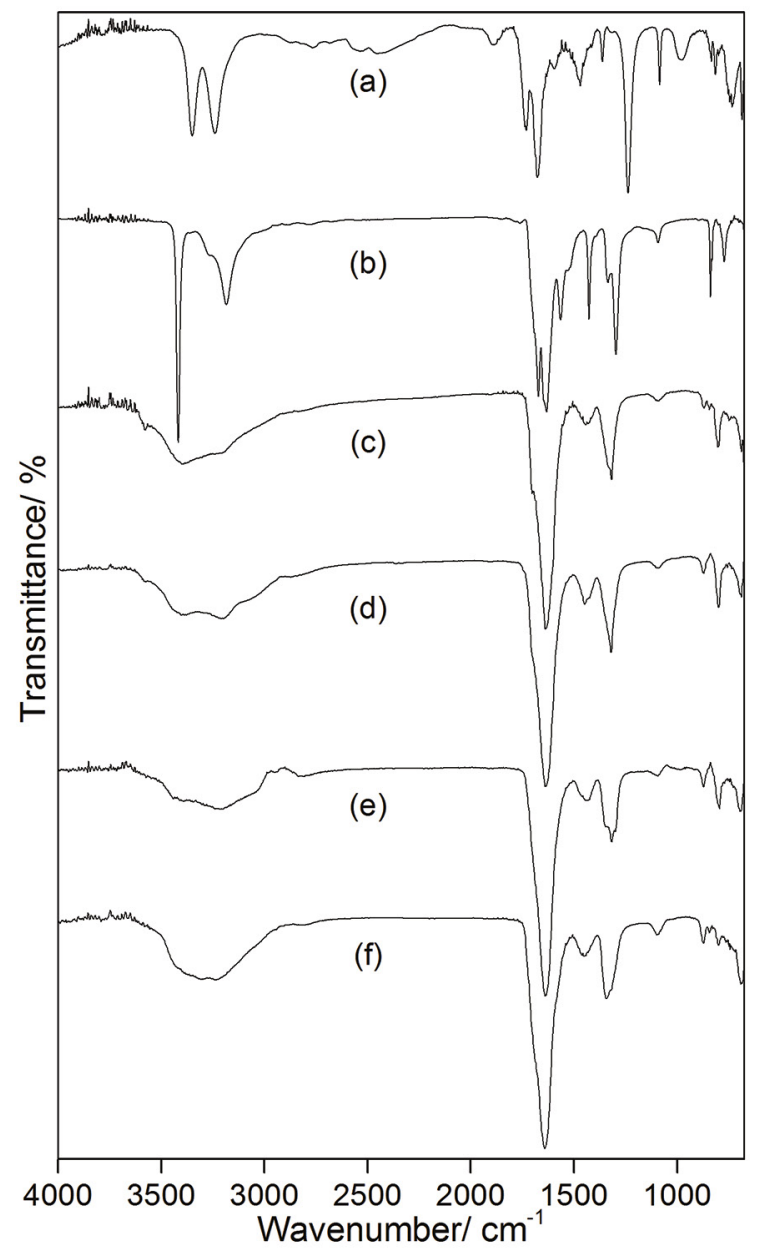

Furthermore, as shown in Table 3, the asymmetric stretching frequency of the carboxylate group (vas $\mathrm{COO}^{-}$) and the stretching frequency of the amide carbonyl group ( $v \mathrm{C}=\mathrm{O}$, amide band) are shifted to the lower energy region (lower frequency) compared to the oxamic acid. These data suggest that both the amide group and the carboxylate group participate in the coordination. These experimental results are in agreement with theoretical calculations (Figure 3a) and with results of structure determination ${ }^{1}$. It is possible to observe that the frequency values are close to those observed for the sodium salt, which suggests a higher ionic character of the bonds in these complexes, a characteristic property of rare earth complexes ${ }^{22}$.

\section{4. $P X R D$}

The X-ray diffractograms are presented in supplementary material (Figure S1). These results show that holmium and yttrium complexes were obtained with low degree of crystallinity. On the other hand, the complexes of $\mathrm{Tb}$ and

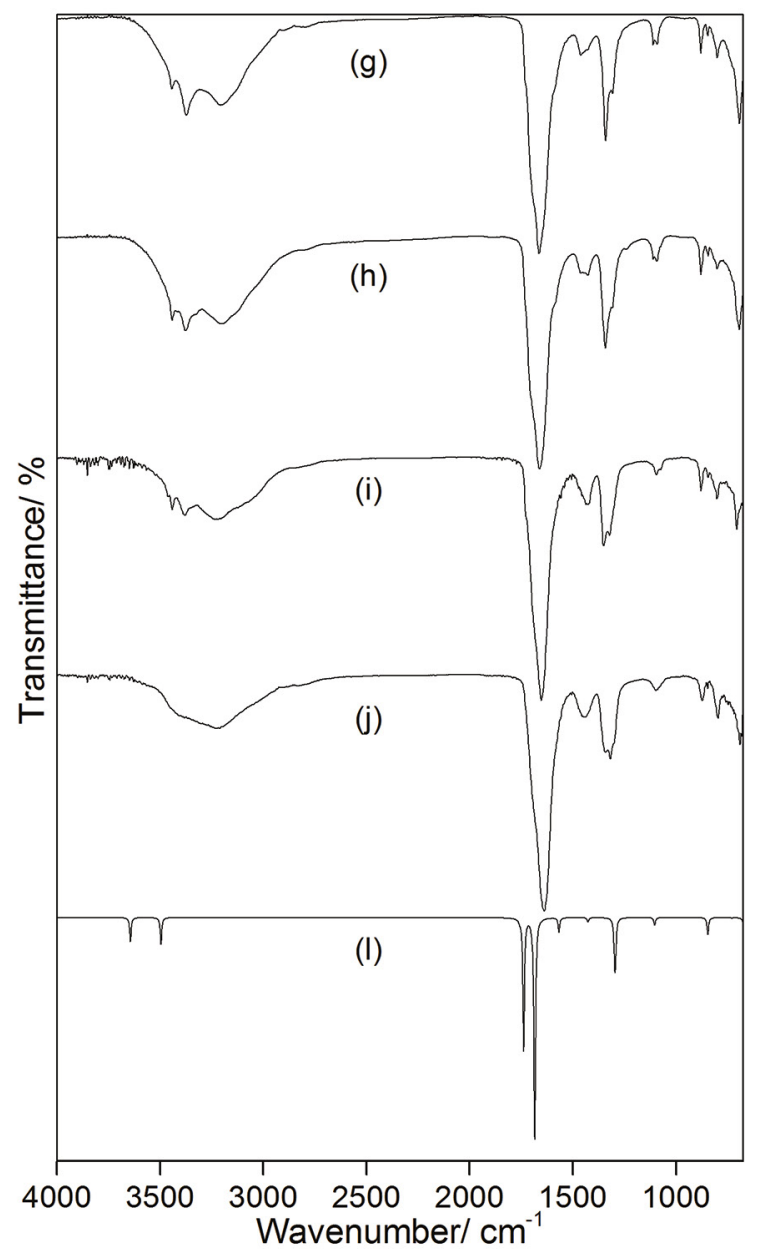

Figure 4. IR spectra of (a) oxamic acid, (b) sodium oxamate and of the complexes of: (c) Tb, (d) Dy, (e) Ho, (f) Er, (g) Tm, (h) Yb, (i) $\mathrm{Lu}$, (j) Y and (1) Y theoretical. 
Table 3. Main vibrational frequencies in infrared of the oxamate complexes of lanthanides and yttrium.

\begin{tabular}{|c|c|c|c|c|c|c|c|c|c|}
\hline \multirow{2}{*}{ Assignments } & \multicolumn{9}{|c|}{ Frequencies } \\
\hline & $\mathrm{Tb}$ & Dy & Ho & $\mathrm{Er}$ & $\mathrm{Tm}$ & $\mathrm{Yb}$ & $\mathrm{Lu}$ & $\mathrm{Y}$ & $\mathrm{Y}^{*}$ \\
\hline$v \mathrm{O}-\mathrm{H}\left(\mathrm{H}_{2} \mathrm{O}\right)$ & $3394_{\mathrm{m}, \mathrm{br}}$ & $3390_{\mathrm{m}, \mathrm{br}}$ & $3213_{\mathrm{m}, \mathrm{br}}$ & $3307_{\mathrm{m}, \mathrm{br}}$ & $3208_{\mathrm{m}, \mathrm{br}}$ & $3208_{\mathrm{m}, \mathrm{br}}$ & $3220_{\mathrm{m}, \mathrm{br}}$ & $3226_{\mathrm{m}, \mathrm{al}}$ & \\
\hline vas $\mathrm{NH}_{2}$ & overlapped & overlapped & overlapped & overlapped & $3443_{\mathrm{m}}$ & $3442_{\mathrm{m}}$ & $3442_{\mathrm{m}}$ & overlapped & $\begin{array}{l}3646, \\
3644, \\
3643\end{array}$ \\
\hline$v \mathrm{~s} \mathrm{NH}_{2}$ & overlapped & overlapped & overlapped & overlapped & $3372_{\mathrm{m}}$ & $3376_{\mathrm{m}}$ & $3381_{\mathrm{m}}$ & overlapped & $\begin{array}{l}3497, \\
3496, \\
3495\end{array}$ \\
\hline $\begin{array}{l}\text { vas } \mathrm{COO}+ \\
\delta_{\mathrm{s}} \mathrm{NH}_{2}\end{array}$ & $1702_{\mathrm{sh}}$ & $1701_{\mathrm{sh}}$ & overlapped & overlapped & overlapped & overlapped & overlapped & overlapped & $\begin{array}{l}1758 \\
1738 \\
1737\end{array}$ \\
\hline $\begin{array}{l}v \mathrm{C}=\mathrm{O}\left(\mathrm{CONH}_{2},\right. \\
\text { Amide I band })\end{array}$ & $1638_{\mathrm{vs}}$ & $1638_{\mathrm{vs}}$ & $1639_{\mathrm{vs}}$ & $1641_{\mathrm{vs}}$ & $1633_{\mathrm{vs}}$ & $1661_{\mathrm{vs}}$ & $1653_{\mathrm{vs}}$ & $1638_{\mathrm{vs}}$ & $\begin{array}{l}1699, \\
1686, \\
1683\end{array}$ \\
\hline$\delta_{\mathrm{s}} \mathrm{NH}_{2}$ & overlapped & overlapped & overlapped & overlapped & overlapped & overlapped & overlapped & overlapped & $\begin{array}{l}1567, \\
1566\end{array}$ \\
\hline$\delta_{\mathrm{s}} \mathrm{NH}_{2}+v \mathrm{C}-\mathrm{N}$ & $1442_{\mathrm{w}}$ & $1447_{\mathrm{w}}$ & $1434_{w}$ & $1452_{w}$ & $1461_{w}$ & $1427_{w}$ & $1426_{w}$ & $1437_{w}$ & $\begin{array}{l}1428 \\
1426 \\
1425\end{array}$ \\
\hline $\begin{array}{l}\text { vs } \mathrm{COO}^{-}+ \\
\delta_{\mathrm{s}} \mathrm{NH}_{2}\end{array}$ & $1318_{\mathrm{m}}$ & $1320_{\mathrm{m}}$ & $1317_{\mathrm{m}}$ & $1342_{\mathrm{m}}$ & $\begin{array}{l}1341_{\mathrm{m}} \\
1308_{\mathrm{m}}\end{array}$ & $\begin{array}{l}1342_{\mathrm{m}} \\
1310_{\mathrm{m}}\end{array}$ & $\begin{array}{l}1351_{\mathrm{m}} \\
1322_{\mathrm{m}}\end{array}$ & $1318_{\mathrm{m}}$ & $\begin{array}{l}1300, \\
1295 \\
1291\end{array}$ \\
\hline $\begin{array}{l}\rho \mathrm{NH}_{2}+v \mathrm{C}=\mathrm{O} \\
\text { (amide) }+v \mathrm{C}-\mathrm{N}\end{array}$ & $1092_{\mathrm{vw}}$ & $1091_{\mathrm{vw}}$ & $1093_{\mathrm{vw}}$ & $1098_{\mathrm{vw}}$ & $\begin{array}{l}1110_{\mathrm{vw}} \\
1091_{\mathrm{vw}}\end{array}$ & $\begin{array}{l}1110_{\mathrm{vw}} \\
1093_{\mathrm{vw}}\end{array}$ & $1094_{\mathrm{vw}}$ & $1098_{\mathrm{vw}}$ & $\begin{array}{l}1105, \\
1104, \\
1102\end{array}$ \\
\hline
\end{tabular}

* theoretical; $\delta_{\mathrm{s}}$ : symmetrical angular in plane deformation; $\rho$ : asymmetric angular in plane deformation; L: oxamate; br: broad; vw: very week; w: week; m: medium; s: strong; vs: very strong.

Lu were obtained with high degree of crystallinity and the diffractograms for the complexes $\mathrm{Tm}, \mathrm{Yb}$ and Lu suggest the formation of an isomorphous series.

\section{Conclusion}

The oxamates of heavy trivalent lanthanides and yttrium were synthesized and characterized by TG-DSC, vibrational spectroscopy in the infrared region (IR), elemental analysis, powder X-ray diffraction and EDTA complexometric titrations.

Based on the TG curves, elemental analysis and complexometric titration results, a general empirical formula could be established for the synthesized complexes as $\mathrm{Ln}(\mathrm{L})_{3} \cdot n \mathrm{H}_{2} \mathrm{O}$, in which $\mathrm{Ln}$ represents heavy trivalent lanthanides, $\mathrm{L}$ is oxamate and $n=1$ (Dy, Ho, Y); 1.25 (Er); 1.5 (Tb and Lu); 2 (Tm) and $2.5(\mathrm{Yb})$.

Simultaneous TG-DSC curves provided information about the thermal behavior of these complexes: dehydration, thermal stability and thermal decomposition steps.

The main gaseous products released during the thermal decomposition were identified as ammonia, hydrogen cyanide, nitrous oxides, $\mathrm{CO}_{2}$ and $\mathrm{CO}$.

The experimental and theoretical infrared spectroscopic data suggest that the oxamate acts as a chelating bidentate ligand to the metal ions through the oxygen of the amide and carboxylate groups. Furthermore, the great similarity between the experimental infrared spectra for all the complexes suggests that all are coordinated in the same way.

\section{Acknowledgements}

The authors thank FAPESP, CNPq and CAPES Foundations (Brazil) for financial support. This research was supported by resources supplied by the Center for Scientific Computing (NCC/Grid UNESP) of the São Paulo State University (UNESP), Instituto de Química de Araraquara, UNESP Campus de Araraquara and CENAPAD-UNICAMP.

\section{References}

1. Papadimitriou C, Veltsistas P, Marek J, Woollins JD. The preparation and X-ray structure of $\left[\mathrm{Ho}(\text { oxam })_{3}\left(\mathrm{H}_{2} \mathrm{O}\right)_{3}\right]_{4} \cdot 2.75 \mathrm{H}_{2} \mathrm{O}$. Inorganica Chimica Acta. 1998;267(2):299-303.

2. Vansant C, Desseyn HO, Perlepes SP. The synthesis, spectroscopic and thermal study of oxamic acid compounds of some metal(II) ions. Transition Metal Chemistry. 1995;20(5):454-459.

3. Lazaridou V, Perlepes SP, Tsangaris JM. Synthesis, physical properties and spectroscopic studies of oxamato (- 1) lanthanide(III) complexes. Journal of the Less Common Metals. 1990;158(1):1-14.

4. Veltsistas PG, Christos PD, Karayannis MI. Synthesis and $\mathrm{X}$-ray structure of an (oxamato)praseodymium polymer, 
$\left[\operatorname{Pr}\left(\mathrm{HNCOCO}_{2}\right) 1.5\left(\mathrm{H}_{2} \mathrm{O}\right)_{3}\right]_{\mathrm{n}} \cdot 2.75 \mathrm{H}_{2} \mathrm{O}$. Polyhedron. 1995;14(9):1251-1253.

5. Veltsistas PG, Papadimitriou CD, Slawin AMZ, Woollins JD. Synthesis, Characterization and X-Ray Structural Determination of the Nine-coordinate Tris-aqua Tetra-oxamato Neodymium(III) Complex $\left[\mathrm{Nd}(\mathrm{Hoxm})_{3}\left(\mathrm{H}_{2} \mathrm{oxm}\right) \cdot 2.5 \mathrm{H}_{2} \mathrm{O}\right]_{n}$. Journal of Chemical Research, Synopses. 1999;3:222-223.

6. Caires FJ, Lima LS, Gomes DJC, Gigante AC, Treu-Filho $\mathrm{O}$, Ionashiro M. Thermal and spectroscopic studies of solid oxamate of light trivalent lanthanides. Journal of Thermal Analysis and Calorimetry. 2013;111(1):349-355.

7. Becke AD. Density-functional thermochemistry. III. The role of exact exchange. The Journal of Chemical Physics. 1993;98(7):5648.

8. Lee C, Yang W, Parr RG. Development of the Colic-Salvetti correlation-energy formula into a functional of the electron density. Physical Review B. 1988;37(2):785-789.

9. Treu-Filho O, Pinheiro JC, da Costa EB, Ferreira JEV, Figueiredo $\mathrm{AF}$, Kondo RT, et al. Experimental and theoretical study of the compound $[\mathrm{Pd}(\mathrm{dmba})(\mathrm{NCO})(\mathrm{imz})]$. Journal of Molecular Structure. 2007;829(1-3):195-201.

10. Filho OT, Pinheiro JC, Kondo RT. Designing Gaussian basis sets to the theoretical study of the piezoelectric effect of perovskite $\left(\mathrm{BaTiO}_{3}\right)$. Journal of Molecular Structure: THEOCHEM. 2004;671(1-3):71-75.

11. Treu Filho O, Pinheiro J, Kondo R, Marques RF, Paiva-Santos C, Davolos M, et al. Gaussian basis sets to the theoretical study of the electronic structure of perovskite $\left(\mathrm{LaMnO}_{3}\right)$. Journal of Molecular Structure: THEOCHEM. 2003;631(1-3):93-99.

12. Frisch MJ, Trucks GW, Schlegel HB, Scuseria GE, Robb MA, Cheeseman JR, et al. Gaussian 09, Revision A.02. Wallingford: Gaussian, Inc.; 2009.

13. Goodson D, Sarpal SK, Bopp P, Wolfsberg M. Influence on isotope effect calculations of the method of obtalnlng force constants from vibrational data. The Journal of Physical Chemistry. 1982;86(5):659-663.

14. Schelege HB. Some Practical Suggestions for Optimizing Geometries and Locating Transition States. In: Bertrán J, Csizmadia IG, eds. New Theoretical Concepts for Understanding Organic Reactions. Dordrecht: Springer; 1989. p. 33-53.
15. Dennington R, Keith T, Millam J. GaussView, Version 5.0.8. Shawnee Mission: Semichem Inc.; 2009.

16. Alves FS, Bembo LH, Caires FJ, Ionashiro EY. Thermoanalytical study of heavier trivalent lanthanides fumarates. Journal of Thermal Analysis and Calorimetry. 2013;113(2):739-744.

17. Caires FJ, Gigante AC, Gomes DJC, Treu-Filho O, Ionashiro M. Synthesis, thermal behavior and spectroscopic study of trivalentlanthanide and yttrium(III) $\alpha$-hydroxyisobutyrates, in solid state. Thermochimica Acta. 2013;569:8-16.

18. Nunes WDG, Teixeira JA, do Nascimento ALCS, Caires FJ, Ionashiro EY, Ionashiro M. A comparative study on thermal behavior of solid-state light trivalent lanthanide isonicotinates in dynamic dry air and nitrogen atmospheres. Journal of Thermal Analysis and Calorimetry. 2016;125(1):397-405.

19. Locatelli JR, Ionashiro EY, Caires FJ, Carvalho CT. Synthesis, Characterization and Thermal Behavior of Solid-State Compounds of Light Trivalent Lanthanide Malonates. Brazilian Journal of Thermal Analysis. 2013;2(1):23-30.

20. Silverstein RM, Webster FX, Kiemle DJ. Spectrometric identification of organic compounds. $7^{\text {th }}$ ed. Hoboken: Wiley; 2005. $512 \mathrm{p}$

21. Nakamoto K. Infrared and Raman spectra of inorganic and coordination compounds: Part A: Theory and Applications in Inorganic Chemistry. $6^{\text {th }}$ ed. Hoboken: Wiley; 2009.

22. Bünzli JCG. On the design of highly luminescent lanthanide complexes. Coordination Chemistry Reviews. 2015;293294:19-47.

\section{Supplementary material}

The following online material is available for this article:

Table S1. Selected optimized geometrical parameters for the yttrium complex in the ground state calculated at B3LYP levels.

Figure S1. X-ray powder diffraction patterns of the compounds: (a) $\mathrm{Tb}(\mathrm{L})_{3} \cdot 1.5 \mathrm{H}_{2} \mathrm{O}$, (b) $\mathrm{Dy}(\mathrm{L})_{3} \cdot 1 \mathrm{H}_{2} \mathrm{O}$, (c) $\mathrm{Ho}(\mathrm{L})_{3} \cdot 1 \mathrm{H}_{2} \mathrm{O}$, (d) $\mathrm{Er}(\mathrm{L})_{3} \cdot 1.25 \mathrm{H}_{2} \mathrm{O}$, (e) $\mathrm{Tm}(\mathrm{L})_{3} \cdot 2 \mathrm{H}_{2} \mathrm{O}$, (f) $\mathrm{Yb}(\mathrm{L})_{3} \cdot 2.5 \mathrm{H}_{2} \mathrm{O}$, (g) $\mathrm{Lu}(\mathrm{L})_{3} \cdot 1.5 \mathrm{H}_{2} \mathrm{O}$ and (h) $\mathrm{Y}(\mathrm{L})_{3} \cdot 1 \mathrm{H}_{2} \mathrm{O}$. 